\title{
Modeling of Thermophysical and Mechanical Phenomena in Dissimilar Welded Joints
}

\author{
W. PiekARSKA* AND Z. SATERnUs \\ Czestochowa University of Technology, 42-201 Czestochowa, Poland \\ Doi: $10.12693 /$ APhysPolA.138.324 \\ *e-mail: piekarska@imipkm.pcz.pl
}

\begin{abstract}
Thermophysical and mechanical phenomena occurring in steel during welding process depend on the type of steel, determined by its chemical composition. During welding of two steels, several issues arise when one steel changes its structure composition during heating and cooling and the other does not change the structure. Changes in microstructure of steel are caused by phase transformations in solid state. In spite of thermal strain, these phase transformations generate additional deformations. The formation of various deformations causes the total deformation of welded joint. Numerical modeling of thermomechanical phenomena in welding processes of dissimilar materials using simulation software is one of the most difficult tasks to carry out. Requires the adaption of appropriate material models in the numerical algorithm for each material and the selection of various thermal properties of the process. The paper presents numerical modeling of thermophysical and mechanical phenomena in a welded joint made of two different materials, 304 stainless steel, in which only thermal deformations arise during welding and S355 structural steel, in which thermal strain and structural strain are present. The simulation software includes temperature dependent material properties. Characteristic zones in welded joint are determined on the basis of numerical simulations as well as displacement and stress field.
\end{abstract}

topics: welding, numerical modeling, dissimilar materials, thermomechanical phenomena

\section{Introduction}

Connections of dissimilar materials are used successfully in many modern industries [1, 2]. The welding process of two different materials requires the specifics of each material that is used in one thermal process. One of dissimilar materials joining method is a laser beam welding [3, 4]. An important issue of laser beam welding process is the selection of appropriate welding parameters to achieve the desired quality of the joint $[5,6]$. Experimental determination of these parameters is quite expensive, therefore numerical methods are increasingly used in the industry [6], supplemented by experimental verification of the obtained simulation results $[2,5,7]$.

The paper presents results of numerical modeling of thermomechanical phenomena occurring in the laser beam welding process of the butt joint made of dissimilar materials. Figure 1 presents the scheme of the analyzed system.

Modeled joint consists of two dissimilar sheets with dimensions $L=70 \mathrm{~mm}, s=35 \mathrm{~mm}, g=4 \mathrm{~mm}$ made of X5CrNi18-10 austenitic steel (304 steel) and S355 steel. Process parameters used in calculations are taken from experimental studies. Simulation calculations are carried out in ABAQUS FEA software, based on finite element method (FEM). Material models of joined sheets are taken from works $[6,8]$. A mathematical model of

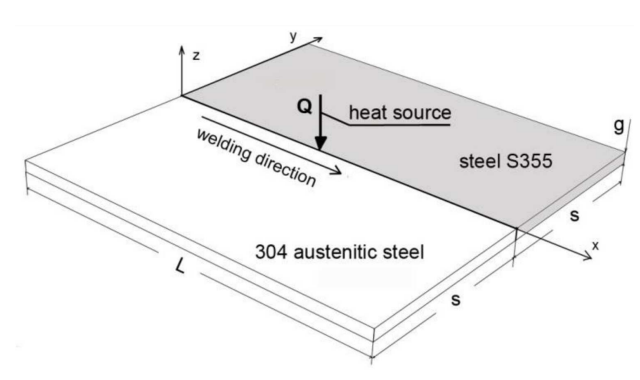

Fig. 1. Scheme of analyzed domain.

a heating source with a Gaussian distribution is adopted $[9,10]$. This heat source model is implemented into solver.

Temperature distribution in the joint is presented in this paper. The shape and size of the melting zone, stress state and displacement field of joint are estimated.

\section{Experiment}

The experimental tests were carried out using Trumpf Lasercell 1005 welding and cutting station at Łukasiewicz Research Network - Institute of Welding. $\mathrm{CO}_{2}$ laser with a maximum beam power of $3800 \mathrm{~W}$ is used in the experiment. During testing 
Process parameters.

TABLE I

\begin{tabular}{c|c|c|c}
\hline \hline $\begin{array}{c}\text { Beam } \\
\text { power }\end{array}$ & Efficiency & $\begin{array}{c}\text { Focal } \\
\text { length }\end{array}$ & $\begin{array}{c}\text { Welding } \\
\text { speed }\end{array}$ \\
\hline $3800 \mathrm{~W}$ & 0.91 & 270 & $1 \mathrm{~m} / \mathrm{min}$
\end{tabular}

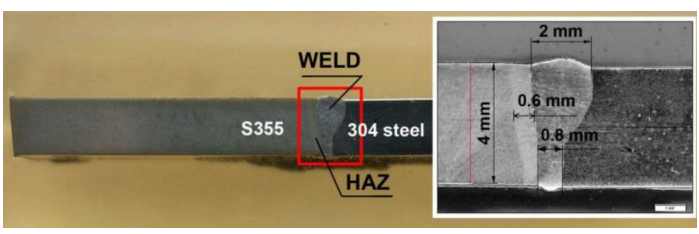

Fig. 2. Macroscopic view of the cross section of the weld.
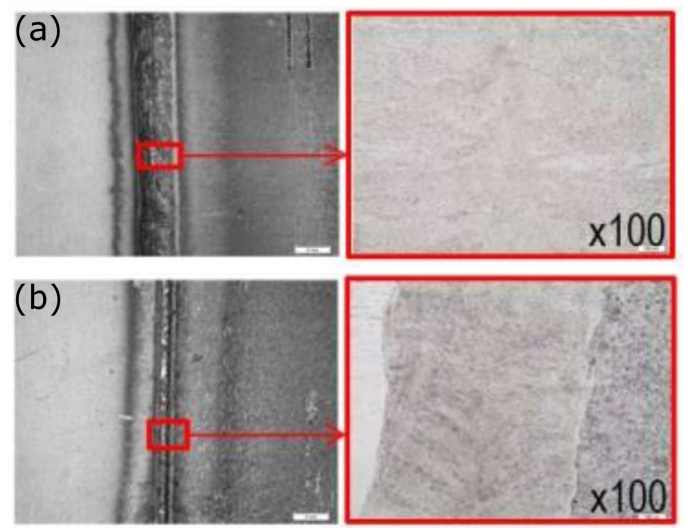

Fig. 3. Microstructures from (a) the face and (b) the ridge of the weld.

two sheets made of dissimilar materials are joined. The dimensions of each sheet are $70 \times 35 \times 4 \mathrm{~mm}^{3}$ (length $\times$ width $\times$ depth). The sheets are made of S355 steel and austenitic steel X5CrNi18-10 (304 steel). Process parameters are presented in Table I.

Shielding gas of helium $(10 \mathrm{l} / \mathrm{min})$ is fed from the face of the weld during the process. No additional material is used.

Metallographic tests are carried out. Macroscopic and microscopic pictures of welded joint are presented in Fig. 2 where each area of welded join is pointed out (weld and heat affected zone). Moreover, the figure shows the geometry of melted zone and occurring in the constructional steel (S355) heat affected zone (HAZ). Figures 3 present examples of joint microstructures from the face and ridge. Microscopic images show a magnification of $\times 100$ of the structure. In this magnification, one can see the microstructure of each material and the weld zone.

\section{Numerical model}

A numerical model of analyzed system is developed in the Abaqus/CAE module. The dimensions and process parameters are the same as in experimental studies. The three-dimensional discrete model of the system is shown in Fig. 4.

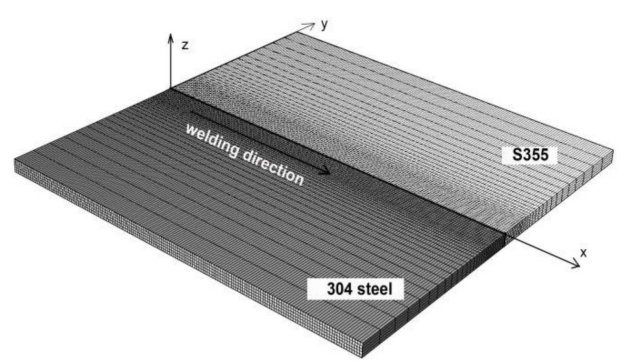

Fig. 4. Three-dimensional discrete model.

The model assumes a change in the mesh density depending on the distance from the welding line. At the welding line (welding plane for $y=0$ ) perfect contact of surfaces is assumed.

The numerical analysis of thermomechanical phenomena is implemented using an uncoupled method in the Abaqus FEA program. The first step is the determination of the temperature field and determination of the shape and width of melting zone. An analysis of mechanical phenomena is carried out in the next step $[6,10]$.

\section{Mathematical modeling}

The heat transfer equation follows the classical equation of energy conservation with Fourier's law $[5,11]$. The heat transfer equation is expressed in the weighted residuum criterion method. The analysis is conducted in Lagrange coordinates, where the coordinates of the center heat source are determined at each time step. Thus,

$$
\begin{gathered}
\int_{V} \rho \frac{\partial U}{\partial t} \delta T \mathrm{~d} V \int_{V} \frac{\partial \delta T}{\partial x_{\alpha}}\left(\lambda \frac{\partial T}{\partial x_{\alpha}}\right) \mathrm{d} V= \\
\int_{V} \delta T q_{V} \mathrm{~d} V+\int_{S} \delta T q_{S} \mathrm{~d} S
\end{gathered}
$$

where $\lambda\left[\mathrm{W} / \mathrm{m}{ }^{\circ} \mathrm{C}\right]$ is a thermal conductivity, $U=U(T)[\mathrm{J} / \mathrm{kg}]$ is a internal energy, $q_{V}\left[\mathrm{~W} / \mathrm{m}^{3}\right]$ is a laser beam heat source, $T=T\left(x_{\alpha}, t\right)\left[{ }^{\circ} \mathrm{C}\right]$ is temperature, $q_{S}\left[\mathrm{~W} / \mathrm{m}^{2}\right]$ is a boundary heat flux, $\delta T$ is a variational function, $\rho\left[\mathrm{kg} / \mathrm{m}^{3}\right]$ is a density, $V\left[\mathrm{~m}^{3}\right]$ is a volume, and $S\left[\mathrm{~m}^{2}\right]$ is surface. The solution of (1) is supplemented by initial and boundary conditions of Dirichlet, Neumann and Newton's type $[5,6,10]$.

Calculations take into account temperature dependent thermophysical properties [6], as well as solidus $T_{S}$ and liquidus $T_{L}$ temperatures, and latent heat $H_{L}$ of fusion:

$$
\begin{aligned}
& \text { - } \mathrm{S} 355-T_{S}=1477^{\circ} \mathrm{C}, T_{L}=1527^{\circ} \mathrm{C}, \\
& H_{L}=270 \times 10^{3} \mathrm{~J} / \mathrm{kg}, \\
& \text { - } 304 \text { steel }-T_{S}=1400^{\circ} \mathrm{C}, T_{L}=1455^{\circ} \mathrm{C}, \\
& \\
& H_{L}=260 \times 10^{3} \mathrm{~J} / \mathrm{kg} .
\end{aligned}
$$

The additional numerical subroutine includes a mathematical model of the heat source with assumed Gaussian distribution [9]. Numerical analysis of thermomechanical phenomena is carried out 


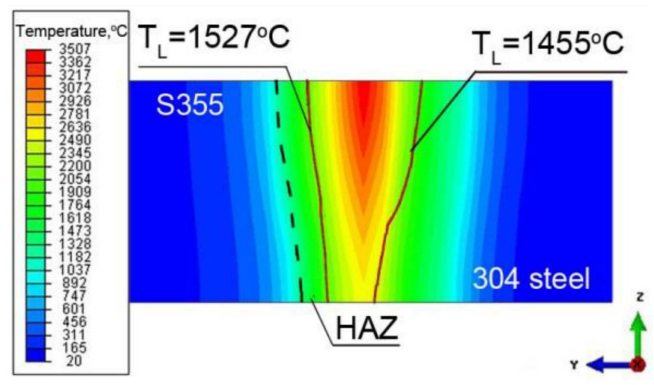

Fig. 5. Temperature distribution in the cross section of the laser welded joint.

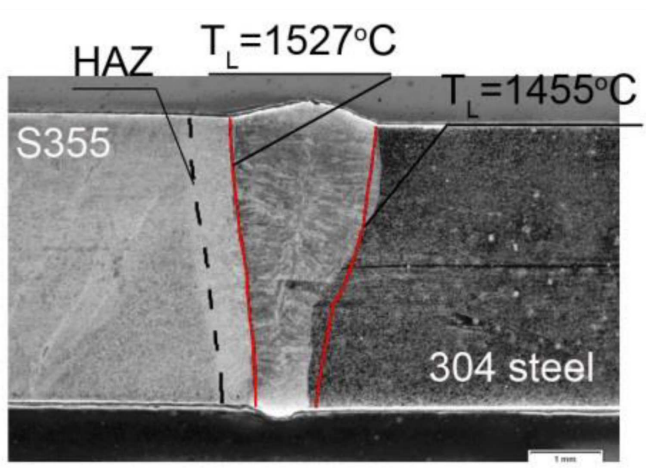

Fig. 6. Comparing the numerically predicted shape of melted zone with the experiment.

in the elastic-plastic range. The solution is based on classical equilibrium equations (2), supplemented with constitutive relations, initial conditions and boundary conditions [12].

$$
\begin{aligned}
& \nabla \circ \dot{\boldsymbol{\sigma}}\left(x_{\alpha}, t\right)=0, \quad \dot{\sigma}_{i j}=\dot{\sigma}_{j i} \\
& \dot{\boldsymbol{\sigma}}=\boldsymbol{D} \circ \dot{\boldsymbol{\varepsilon}}^{e}+\dot{\boldsymbol{D}} \circ \varepsilon^{e}, \quad \varepsilon=\varepsilon^{e}+\varepsilon^{p}+\varepsilon^{T h}
\end{aligned}
$$

where $\sigma=\sigma\left(\sigma_{i j}\right)$ is stress tensor, $x_{\alpha}$ describes location of considered point (material particle), (o) is inner exhaustive product, $\boldsymbol{D}=\boldsymbol{D}(T)$ is a tensor of temperature dependent material properties, $\varepsilon$ is total strain, $\varepsilon^{e}$ is elastic strain, $\varepsilon^{p}$ is plastic strain, and $\varepsilon^{T h}$ is thermal strain.

\section{Results of simulations}

Numerical simulation is carried out on the basis of developed numerical models and accepted mathematical models. Simulations are performed in Abaqus/Standard static analysis simulation module [11]. The calculations assume the same process parameters as they were used in the experiment $(Q=3800 \mathrm{~W}, \eta=0.91, v=1 \mathrm{~m} / \mathrm{min})$. Laser beam radius $r=0.35 \mathrm{~mm}$ and the penetration depth $h=5 \mathrm{~mm}$ are assumed on the basis of verification of numerically obtained results.

Figure 5 presents the numerically estimated temperature field in the cross section of the joint. Boundaries of melted zones and HAZ for S355 steel (in accordance with accepted values of solidus and liquidus temperatures) are pointed out.

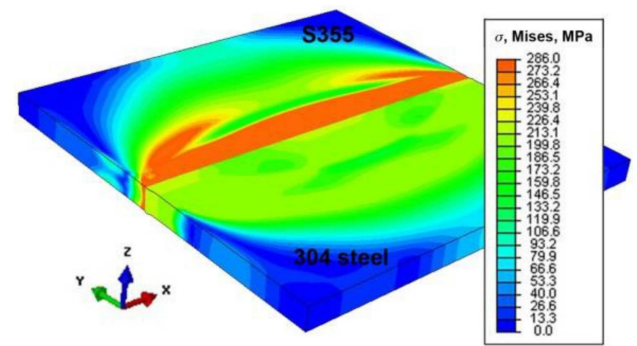

Fig. 7. Reduced residual stress of laser welded joint.

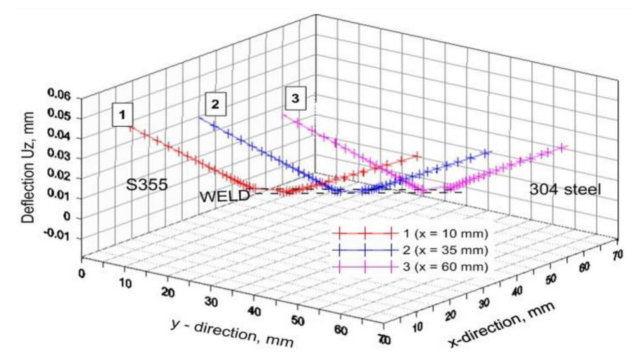

Fig. 8. Distribution of displacement $U_{z}$ for three different lines (1,2, and 3) perpendicular to the welding line.

Figure 6 shows a comparison of numerically predicted shape of the melted zone with a macroscopic image of the joint. Based on the simulation of mechanical phenomena the stress state (Fig. 7) and the displacement field in the joint (Fig. 8) are determined.

\section{Conclusions}

On the basis of obtained results, it can be concluded that much higher stress values occur on the S355 steel. Analyzing the displacement field, it can be noticed that the largest displacements occur in a perpendicular direction to the welding line. The maximum displacement value is $0.056 \mathrm{~mm}$ and occurs on the side of 304 austenitic steel. Numerical modeling of the welding process using commercial software requires the development of appropriate mathematical and numerical models and their implementation into a simulation program. In the case of dissimilar materials it is necessary to take into account relevant material models. The comparison of the numerically predicted shape of the melted zone with experimental studies shows a good agreement.

\section{References}

[1] S. Meco, G. Pardal, S. Ganguly, S. Williams, N. McPherson, Opt. Laser Eng. 67, 22 (2015).

[2] Ch. Shuhai, H. Jihua, X. Jun, Z. Xingke, L. Sanbao, J. Mater. Process. Technol. 222, 43 (2015). 
[3] N. Arivazhagan, S. Singh, S. Prakash, G.M. Reddy, Mater. Des. 32, 3036 (2011).

[4] D. Harwani, K. Int. Banker, J. Eng. Res. Appl. 4(12), 64 (2014).

[5] M. Kubiak, W. Piekarska, Comput. Struct. 172, 29 (2016)10.1007/s10973-012-2486-0.

[6] W. Piekarska, M Kubiak, Z. Saternus, S. Stano, T. Domański, Arch. Metall. Mater. 60(3), 1965 (2015).

[7] Sz. Szávai, Z. Bezi, C. Ohms, Frattura ed Integrità Strutturale 36, 36 (2016).
[8] D. Deng, H. Murakawa, Comput. Mater. Sci. 37, 269 (2006).

[9] S. A. Tsirkas, P. Papanikos, Th. Kermanidis J. Mater. Process. Technol. 134, 59, (2003).

[10] T. Domański, A. Sapietova, M. Saga, Procedia Eng. 177, 64, (2017).

[11] SIMULIA, Abaqus FEA theory manual, Ver. 6.7, Dassault System, 2007.

[12] X. Zhu, Y. Chao, Comput. Struct. 80, 967 (2002). 